\title{
Epigenetics meets estrogen receptor: regulation of estrogen receptor by direct lysine methylation
}

\author{
Qun Zhou', Patrick G Shaw ${ }^{2,3}$ and Nancy E Davidson ${ }^{2,3}$
}

\author{
${ }^{1}$ Department of Biochemistry and Molecular Biology, University of Maryland School of Medicine, Baltimore, \\ Maryland 21201, USA \\ ${ }^{2}$ Department of Biochemistry and Molecular Biology, Johns Hopkins Bloomberg School of Public Health, Baltimore, \\ Maryland 21205, USA \\ ${ }^{3}$ University of Pittsburgh Cancer Institute, UPMC Cancer Pavilion, 5150 Centre Avenue Suite 500, Pittsburgh, \\ Pennsylvania 15232, USA \\ (Correspondence should be addressed to N E Davidson; Email: davidsonne@upmc.edu)
}

\begin{abstract}
The nuclear hormone receptor estrogen receptor $\alpha(E R \alpha)$ promotes cellular growth through liganddependent activation of specific target genes, a process which is targeted in the treatment of $E R \alpha-$ expressing breast cancers. ER $\alpha$ activity is regulated at the protein level by post-translational modifications including phosphorylation and acetylation. A study now shows that $\mathrm{ER} \alpha$ can also be directly methylated at lysine 302 (K302) by SET7, a histone methyltransferase that is known to monomethylate $\mathrm{H} 3 \mathrm{~K} 4$ and is associated with transcriptional activation. It was shown that K302 methylation stabilizes $E R \alpha$ protein and is suggested to increase sensitivity of $E R \alpha$ to estrogens, enhancing transcription of estrogen response elements. Furthermore, SET7 methylation of K302 is enhanced by a breast cancer-associated mutation at K303 (K303R) in vitro. These findings provide an additional mechanism of SET7 mediated transcriptional activation, as well as potential insight into the complex regulation of $\mathrm{ER} \alpha$ stability and ligand sensitivity.
\end{abstract}

Endocrine-Related Cancer (2009) 16 319-323

Estrogens such as $17 \beta$-estradiol $\left(E^{2}\right)$ are synthesized predominantly in ovaries or via aromatization in peripheral tissues and play a pivotal role in the development of breast, ovarian, and endometrial cancers (Yager \& Davidson 2006). The role of ER, particularly ER $\alpha$, and its ligands in breast carcinogenesis has been recognized for some time (Yager \& Davidson 2006). Indeed, about $70 \%$ of newly diagnosed invasive breast cancers express $\mathrm{ER} \alpha$ protein and this expression identifies cancers that are potentially amenable to endocrine approaches designed to deplete ligand or receptor, or impede ligand-receptor interactions. Although other important factors affecting endocrine therapies have come to light in recent years (e.g. HER-2 expression and progesterone receptor status), molecular studies have indicated that $\mathrm{ER} \alpha$-related pathways are a major determinant of endocrine responsiveness (Rastelli \& Crispino 2008).

Much work has focused on mechanisms that regulate ER $\alpha$ expression in human breast cancer cells. It has been hypothesized that epigenetic mechanisms including DNA methylation and/or histone modifications might contribute to silencing of ER $\alpha$ expression (Ottaviano et al. 1994, Leader et al. 2006). Indeed, several studies have demonstrated that the $\mathrm{ER} \alpha \mathrm{CpG}$ island is hypermethylated in $\mathrm{ER} \alpha$-negative human breast cancer cells and treatment of these cells with inhibitors of DNA methyltransferases such as 5-azacitidine or decitabine elicits reexpression of functional $\mathrm{ER} \alpha$ protein. Furthermore, covalent histone modifications, such as the methylation or acetylation of lysine residues, can also contribute to the transcriptional silencing or activation of ER $\alpha$ (Sharma et al. 2006, Macaluso et al. 2007). Site-specific modifications in the $\mathrm{N}$-terminal tail region of core and linker histones specify a histone code of epigenetic regulation that dictates a specific active or inactive chromatin state (Strahl \& Allis 2000). Methylation of lysine residues can occur on histones $\mathrm{H} 3$ and $\mathrm{H} 4$, thereby contributing to a chromatin conformation compatible with either active or repressed gene transcription, depending on the residue modified and the degree of methylation (Sims et al. 2003). In particular, monomethylation at histone $\mathrm{H} 3$ lysine $4(\mathrm{H} 3 \mathrm{~K} 4 \mathrm{Me} 1)$ is associated with transcriptionally competent euchromatin (Noma et al. 2001), but the mechanism of H3K4Me1associated transcriptional activation is poorly understood.

Several histone H3K4-specific methyltransferases have been identified including human SET7 (also known as SET9; 
Wang et al. 2001b). The suppressor of variegation, enhancer of zeste and trithorax (SET) domain is an evolutionarily conserved sequence motif originally described in Drosophila; it is present in chromosomal proteins that function in epigenetic control of gene expression (Jenuwein et al. 1998). Early studies revealed that SET7 activates transcription by preventing chromatin condensation (Wang et al. 2001b, Nishioka et al. 2002). Importantly, SET7 can methylate specific lysines on non-histone proteins including transcriptional factors and regulators like p53 and TAF10. SET7 methylation stabilizes and inhibits nuclear export of $\mathrm{p} 53$, leading to the transcriptional activation of the p53 target genes (Chuikov et al. 2004). Likewise, SET7 methylation has a stimulatory effect on TAF10 mediated transcription by increasing TAF10 affinity for interaction with RNA polymerase II (Kouskouti et al. 2004). These studies suggest that the role of SET7 methylation in transcriptional activation reaches beyond the modification of histones.

Another such non-histone target appears to be ER $\alpha$. Evidence has been emerging that lysine residues in the ER $\alpha$ hinge region can be targets for multiple types of posttranslational modifications (PTMs) including acetylation, phosphorylation, and ubiquitination (Fig. 1). These modifications may affect hormone sensitivity through alteration of ER $\alpha$ stability or regulation of estrogen-dependent gene transcription. Histone acetyltransferases such as p300 and histone deacetylase inhibitors have been shown to induce acetylation at several lysines within the hinge region. Coactivator-dependent acetylation of K266 and K268 by p300 increases ER $\alpha$ transcriptional activity by enhancing DNA binding (Kim et al. 2006), whereas acetylation of K303 may attenuate hormone sensitivity through dissociation of transcriptional coactivators from the promoter (Wang et al. 2001a). Studies have found that hyperphosphorylation of serine at 305 (S305) enhances estrogen-induced transcriptional activity and acetylation of lysine at 303 inhibits S305 phosphorylation (Cui et al. 2004). Other covalent modifications such as ubiquitination at K302 (Berry et al. 2008) and sumoylation at K266 and K268 (Sentis et al. 2005) have also been shown to affect estrogen receptor stability and activity. Together, these data suggest that the complex cellular responses to $\mathrm{E}^{2}$ are significantly affected by PTMs. However, it was not clear how $\mathrm{ER} \alpha$ methylation might play a role in estrogen signaling until Subramanian and colleagues recently presented the first evidence that ER $\alpha$ is regulated by the SET7 lysine methyltransferase in human breast cancer cells (Subramanian et al. 2008). In fact, this is only the second account in the literature of regulation of a nuclear receptor by direct methylation, shortly following the discovery that retinoic acid receptor $\alpha$ activity is regulated by lysine trimethylation (Huq et al. 2007).

Using an in vitro methylation assay of peptide substrates (ER $\alpha$, androgen receptor (AR), glucocorticoid receptor (GR) and mutant $E R \alpha$ ), and recombinant purified HMTases, they found that the methylation of lysine in the ER $\alpha$ hinge region is specifically targeted by SET7. Through mass spectrometric analysis, they identified K302 as the only site of methylation

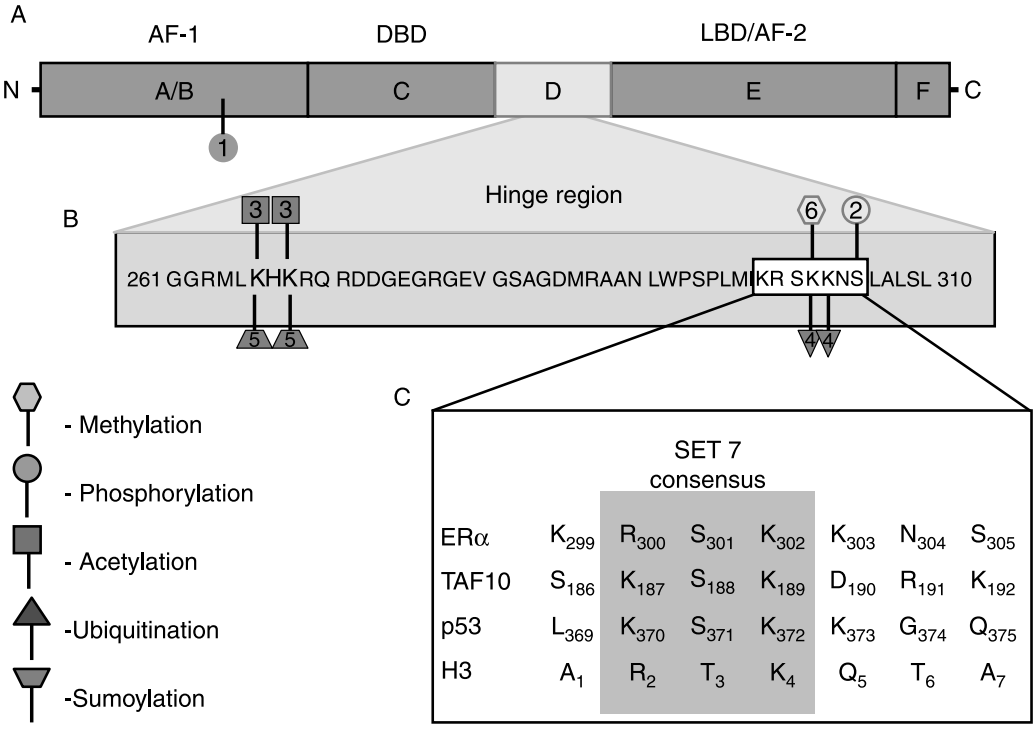

Figure 1 Post-translational modifications of $E R \alpha$. The subdomains of $E R \alpha$ are outlined with some of the major previously identified PTMs annotated with numbered shapes (defined in legend). (A) The major functional domains of ER $\alpha$ are shown. The poorly conserved AF-1 domain lies at the N-terminus, followed by the DNA binding domain (DBD). The C-terminal region of ER $\alpha$ houses the ligand-binding domain (LBD) of hormone receptors which contains the well-conserved AF-2 domain. (B) The DNA and ligand binding regions are connected by the hinge region, expanded to show the various PTM target residues previously identified.

(C) Comparison of the SET7 binding motif for the hinge region of ER $\alpha, \mathrm{TAF} 10, \mathrm{p} 53$, and histone h3 is shown.

The recognition consensus sequence is shaded in grey with the target lysine residues aligned and in bold. The PTMs highlighted above were reported in the following publications: 1, (Ali et al. 1993), 2, (Cui et al. 2004), 3, (Kim et al. 2006), 4, (Sentis et al. 2005), 5, (Berry et al. 2008), 6, (Subramanian et al. 2008). 
by SET7 within the ER $\alpha$ hinge region in vitro. To confirm these findings in vivo, the authors raised a specific antibody against an $\mathrm{ER} \alpha$ peptide that is monomethylated at K302; its specificity and sensitivity for this methylated residue were convincingly demonstrated by dot-blot analysis. They then transiently transfected ER $\alpha$-negative HeLa cells with expression constructs for SET7 and ER $\alpha$, and cell lysates were immunoprecipitated for $\mathrm{ER} \alpha$, followed by western blot analysis. Their findings demonstrate that $\mathrm{ER} \alpha$ is methylated at K302 by SET7 in cell culture and that this methylation can be decreased by mutation of K303 to arginine (K303R). This latter observation is of particular interest because an acquired missense mutation in the $\mathrm{ER} \alpha$ gene resulting in $\mathrm{K} 303 \mathrm{R}$ substitution has been reported in primary breast ductal hyperplasia and cancers from patients in the southern USA (Fuqua et al. 2000, Conway et al. 2005) but not in Japan or the UK (Tokunaga et al. 2004, Davies et al. 2005). These studies lead to the conclusion that SET7 serves as a specific HMTase to monomethylate K302 and SET7-mediated methylation of K302 may be altered by the mutation of the neighboring K303. The structural basis of these findings was elaborated with high-resolution X-ray data from co-crystals of full length SET7 protein with an ER $\alpha$ peptide. The series of structures representing the phases of turnover in $\mathrm{ER} \alpha$ methylation show a salt bridge between ER $\alpha$ N304 and SET7 K317, which is indicative of enhanced SET7 binding (Couture et al. 2006) and another between ER $\alpha$ K303 and SET7 D338, consistent with the in vitro and in vivo observations. A limitation of these studies is that Subramanian et al (2008) were unable to detect methylation of endogenous $\mathrm{ER} \alpha$ in MCF-7 cells, possibly due to celltypespecific dysregulation of $\mathrm{ER} \alpha$ modification. It is also unfortunate that they did not extend any of these studies to other ER $\alpha$-positive human breast cancer cells to determine how general the findings might be.
The role of SET7-mediated methylation in the regulation of $E R \alpha$ function was carefully addressed by the authors. They stably transfected retroviral vectors that contained SET7 shRNA into the ER $\alpha$-positive MCF-7 breast cancer cell line to generate shSET7 knockdown cells. Results show that knockdown of SET7 concomitantly decreases the steadystate levels of $\mathrm{ER} \alpha$ protein but not $\mathrm{ER} \alpha \mathrm{mRNA}$, suggesting that methylation of K302 by SET7 modulates ER $\alpha$ protein stability. Pulse chase experiments confirmed that ER $\alpha$ halflife is decreased by about twofold in shSET7 cells compared with control cells. Consistent with these observations, estrogen response elements (ERE)-coupled luciferase reporter assays showed that estrogen-driven transcription is dramatically inhibited in shSET7 knockdown clones. Further estrogen-induced transactivation of two classic endogenous ER $\alpha$ target genes, PS2 and PgR, was blunted in shSET7 cells, suggesting that SET7 is required for estrogen-induced transcriptional response. One potential mechanism of SET7 mediated enhancement of ERE transcription is through alteration of protein binding complexes in the ER $\alpha$ target gene promoters. Therefore, the authors used quantitative chromatin immunoprecipitation (ChIP) assays to determine that SET7 regulates ER $\alpha$ target genes by altering ER $\alpha$ binding to target gene regulatory sequences. Furthermore, they established that $\mathrm{ER} \alpha$ and NCoA2 but not SET7 act as coactivators at the PS2 gene promoter in multiple cell lines. However, this does not preclude the possibility that SET7 could act on ER co-factors in addition to $\mathrm{ER} \alpha$, a matter that will not be resolved until the non-histone targets of SET7 are extensively studied.

This study by Subramanian and colleagues has substantially enhanced our knowledge of the role of PTMs of ER $\alpha$ hinge region in the estrogen-dependent gene transcription pathway. Also, the stabilization of ER $\alpha$ by SET7 provides additional complexity to a new-found dimension of the epigenetic code, whereby specific PTMs of transcription

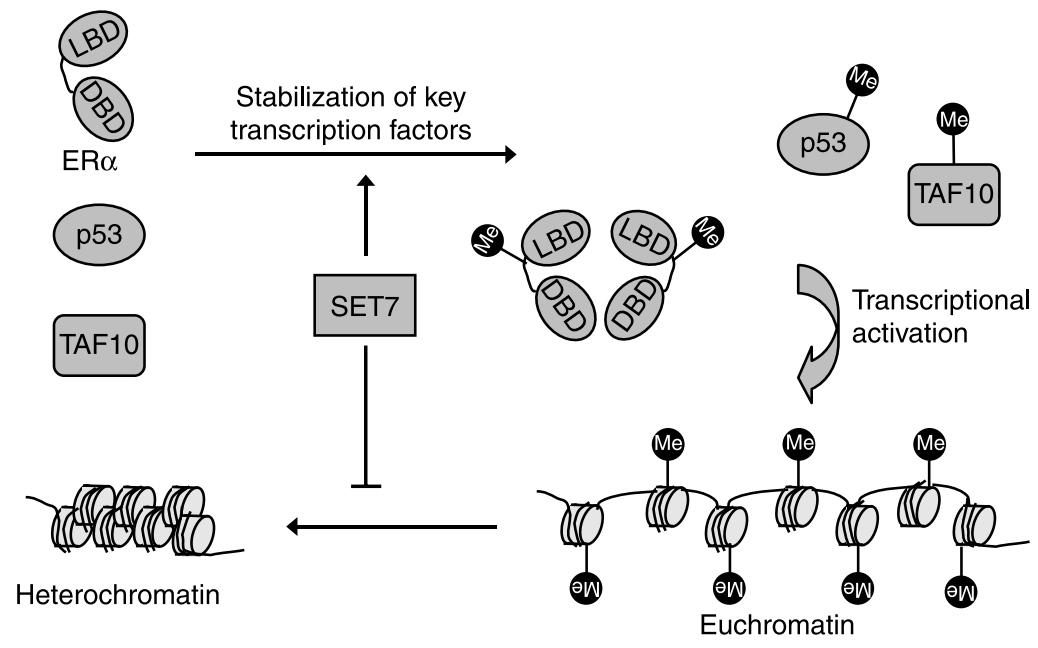

Figure 2 SET7 methylates multiple target proteins to activate transcription. H3K4 methylation by SET7 facilitates gene transcription by preventing chromatin condensation, while SET7 methylation of transcription factors such as p53, TAF10, and ER $\alpha$ enhances their ability to serve as transcriptional activators. 
factors could make a significant contribution to the transcriptional activity commonly attributed to a specific histone modification (Fig. 2). These findings raise important questions, some relevant to the field of epigenomics as well as molecular endocrinology. First, to what extent is the SET7 induced upregulation of ERE transcription responsible for the transcriptional activation-associated with concordant $\mathrm{H} 3 \mathrm{~K} 4$ monomethylation in ER $\alpha$-expressing tissues? Also, what of the reverse? Does SET7 activity play a role in $\mathrm{ER} \alpha$ dependent proliferation of breast cancer, or resistance to endocrine therapies? The answers to these questions could determine the potential of SET7 as a target for breast, or other endocrine-related cancers. Also, as noted earlier, extension of these studies to other cell lines is extremely important to show, whether the findings are general and to understand what other cell-type factors might play a role. Indeed, other studies have shown that, in addition to nuclear gene transcription, $\mathrm{ER} \alpha$ carries out various cellular functions at the plasma membrane and the mitochondria in a celltypespecific manner (Zhang et al. 2002, Pedram et al. 2006). It is quite plausible that the cellular localization and function of $\mathrm{ER} \alpha$ is regulated by specific PTMs as well.

This study is one of several suggesting that PTMs of ER $\alpha$ may play a role in hormone response. Methylation of K302 is of particular interest in view of reports that the functional consequences may be of substantial impact and may be modulated by the adjacent K303R variant that has been reported in human breast cancers, especially those with more aggressive clinical features and poorer prognosis. Thus, these findings may ultimately lead to the development of new anticancer therapies that specifically manipulate SET7 and alter estrogen-signaling pathways.

\section{Declaration of interest}

The authors declare that there is no conflict of interest that could be perceived as prejudicing the impartiality of the research reported.

\section{Funding}

This work was in part supported by grants from Flight Attendants Medical Research Initiative (YCSA072084 (Q Zhou)), National Institutes of Health (T32 CA09110 (P G Shaw) and NIH CA88843 (N E Davidson)), and the Breast Cancer Research Foundation.

\section{References}

Ali S, Metzger D, Bornert JM \& Chambon P 1993 Modulation of transcriptional activation by liganddependent phosphorylation of the human oestrogen receptor A/B region. The EMBO Journal 12 1153-1160.

Berry NB, Fan M \& Nephew KP 2008 Estrogen receptoralpha hinge-region lysines 302 and 303 regulate receptor degradation by the proteasome. Molecular Endocrinology 22 1535-1551.
Chuikov S, Kurash JK, Wilson JR, Xiao B, Justin N, Ivanov GS, McKinney K, Tempst P, Prives C, Gamblin SJ, Barlev NA \& Reinberg D 2004 Regulation of p53 activity through lysine methylation. Nature 432 353-360.

Conway K, Parrish E, Edmiston SN, Tolbert D, Tse CK, Geradts J, Livasy CA, Singh H, Newman B \& Millikan RC 2005 The estrogen receptor-alpha A908G (K303R) mutation occurs at a low frequency in invasive breast tumors: results from a population-based study. Breast Cancer Research 7 871-880.

Couture JF, Collazo E, Hauk G \& Trievel RC 2006 Structural basis for the methylation site specificity of SET7/9. Nature Structural and Molecular Biology 13 140-146.

Cui Y, Zhang M, Pestell R, Curran EM, Welshons WV \& Fuqua SA 2004 Phosphorylation of estrogen receptor alpha blocks its acetylation and regulates estrogen sensitivity. Cancer Research 64 9199-9208.

Davies MP, O’Neill PA, Innes H \& Sibson DR 2005 Hypersensitive K303R oestrogen receptor-alpha variant not found in invasive carcinomas. Breast Cancer Research 7 113-118.

Fuqua SA, Wiltschke C, Zhang QX, Borg A, Castles CG, Friedrichs WE, Hopp T, Hilsenbeck S, Mohsin S, O'Connell P \& Allred DC 2000 A hypersensitive estrogen receptor-alpha mutation in premalignant breast lesions. Cancer Research 60 4026-4029.

Huq MD, Tsai NP, Khan SA \& Wei LN 2007 Lysine trimethylation of retinoic acid receptor-alpha: a novel means to regulate receptor function. Molecular \& Cellular Proteomics 6 677-688.

Jenuwein T, Laible G, Dorn R \& Reuter G 1998 SET domain proteins modulate chromatin domains in eu- and heterochromatin. Cellular and Molecular Life Sciences 54 80-93.

Kim MY, Woo EM, Chong YT, Homenko DR \& Kraus WL 2006 Acetylation of estrogen receptor alpha by p300 at lysines 266 and 268 enhances the deoxyribonucleic acid binding and transactivation activities of the receptor. Molecular Endocrinology 20 1479-1493.

Kouskouti A, Scheer E, Staub A, Tora L \& Talianidis I 2004 Gene-specific modulation of TAF10 function by SET9mediated methylation. Molecular Cell 14 175-182.

Leader JE, Wang C, Popov VM, Fu M \& Pestell RG 2006 Epigenetics and the estrogen receptor. Annals of the New York Academy of Sciences 1089 73-87.

Macaluso M, Montanari M, Noto PB, Gregorio V, Bronner C \& Giordano A 2007 Epigenetic modulation of estrogen receptor-alpha by $\mathrm{pRb}$ family proteins: a novel mechanism in breast cancer. Cancer Research 67 7731-7737.

Nishioka K, Chuikov S, Sarma K, Erdjument-Bromage H, Allis CD, Tempst P \& Reinberg D 2002 Set9, a novel histone H3 methyltransferase that facilitates transcription by precluding histone tail modifications required for heterochromatin formation. Genes \& Development 16 479-489.

Noma K, Allis CD \& Grewal SI 2001 Transitions in distinct histone $\mathrm{H} 3$ methylation patterns at the heterochromatin domain boundaries. Science 293 1150-1155. 
Ottaviano YL, Issa JP, Parl FF, Smith HS, Baylin SB \& Davidson NE 1994 Methylation of the estrogen receptor gene $\mathrm{CpG}$ island marks loss of estrogen receptor expression in human breast cancer cells. Cancer Research 54 2552-2555.

Pedram A, Razandi M, Wallace DC \& Levin ER 2006 Functional estrogen receptors in the mitochondria of breast cancer cells. Molecular Biology of the Cell 7 2125-2137.

Rastelli F \& Crispino S 2008 Factors predictive of response to hormone therapy in breast cancer. Tumori 94 370-383.

Sentis S, Le Romancer M, Bianchin C, Rostan MC \& Corbo L 2005 Sumoylation of the estrogen receptor alpha hinge region regulates its transcriptional activity. Molecular Endocrinology 19 2671-2684.

Sharma D, Saxena NK, Davidson NE \& Vertino PM 2006 Restoration of tamoxifen sensitivity in estrogen receptornegative breast cancer cells: tamoxifen-bound reactivated ER recruits distinctive corepressor complexes. Cancer Research 66 6370-6378.

Sims RJ, Nishioka K \& Reinberg D 2003 Histone lysine methylation: a signature for chromatin function. Trends in Genetics 19 629-639.

Strahl BD \& Allis CD 2000 The language of covalent histone modifications. Nature 403 41-45.

Subramanian K, Jia D, Kapoor-Vazirani P, Powell DR, Collins RE, Sharma D, Peng J, Cheng X \& Vertino PM
2008 Regulation of estrogen receptor alpha by the SET7 lysine methyltransferase. Molecular Cell 30 336-347.

Tokunaga E, Kimura Y \& Maehara Y 2004 No hypersensitive estrogen receptor-alpha mutation (K303R) in Japanese breast carcinomas. Breast Cancer Research and Treatment 84 289-292.

Wang C, Fu M, Angeletti RH, Siconolfi-Baez L, Reutens AT, Albanese C, Lisanti MP, Katzenellenbogen BS, Kato S \& Hopp T 2001 $a$ Direct acetylation of the estrogen receptor alpha hinge region by p300 regulates transactivation and hormone sensitivity. The Journal of Biological Chemistry 276 18375-18383.

Wang H, Cao R, Xia L, Erdjument-Bromage H, Borchers C, Tempst P \& Zhang Y $2001 b$ Purification and functional characterization of a histone H3-lysine 4-specific methyltransferase. Molecular Cell 8 1207-1217.

Yager JD \& Davidson NE 2006 Estrogen carcinogenesis in breast cancer. The New England Journal of Medicine 354 270-282.

Zhang Z, Maier B, Santen RJ \& Song RX 2002 Membrane association of estrogen receptor alpha mediates estrogen effect on MAPK activation. Biochemical and Biophysical Research Communications 294 926-933. 